\title{
Subjective well-being and personality: implications for wellness tourism
}

\author{
I. G. Malkina-Pykh \& Y. A. Pykh \\ Research Center for Interdisciplinary Environmental Cooperation, \\ Russian Academy of Sciences (INENCO RAS), Russia
}

\begin{abstract}
The aims of this study are to demonstrate that 1) personality differences can be considered as the mechanisms underlying differences in subjective well-being and 2) rhythmic movement therapy (RMT) can be regarded as an effective tool for increasing subjective well-being (SWB) in the wellness tourism context. The proposed operationalisation of SWB includes five domains and several psychological constructs that are hypothesised to be components of a mental map, underlying SWB. A total of 213 subjects were recruited among those searching for psychological counselling and assessed with the appropriate questionnaires. Two groups were formed in accordance with their SWB level: group 1 - (very low, low and medium SWB levels) - 96 subjects, 75 females, 21 males, mean age 36, $3 \pm 11,0$ years) and group $2-$ (high and very high SWB levels) - 117 subjects, 96 females, 21 males, mean age 36, $8 \pm 8$, 68 years. ANOVA analyses with the SWB group as a factor revealed significant differences in all psychological variables in two groups except for personal standards. ANOVA analyses with gender as a factor revealed no differences in psychological variables except for body image dissatisfaction. The theoretical background for RMT as an effective part of a wellness service was provided. Our research provides evidence that thinking styles (mental models) may significantly influence SWB and any program used for increasing SWB must include a mental healing service.
\end{abstract}

Keywords: subjective well-being, leisure/vacation satisfaction, personality, rhythmic movement therapy, wellness tourism. 


\section{Introduction}

\subsection{Definition of subjective well-being}

Subjective well-being (SWB) refers to a person's declared well-being and is based on an answer to either a single question or a group of questions about his/her subjectively perceived satisfaction with life or happiness. SWB is defined as a multidimensional construct, consisted of three major components satisfaction with life (LS), positive affect (PA), and negative affect (NA) that represent an ongoing state of psychological wellness [1]. More recently, satisfaction in specific life domains (henceforth domain satisfaction (DS), e.g. satisfaction with health) was included in the definition of SWB [2]. Life satisfaction and domain satisfaction are considered cognitive components because they are based on evaluative beliefs (attitudes) about one's life, positive affect and negative affect assess the affective component of SWB [1,2].

Two main theoretical traditions have contributed to the understanding of SWB. A 'bottom up' perspective explained the SWB of individuals by contextual factors and presented it as a linear combination of DS variables. 'Topdown' model proposed by Diener [1] was based on the idea that satisfaction might be determined more by personality characteristics, such as temperament, social comparison, the goal-achievement gap and adaptation, than situational circumstances. However, numerous studies have examined the possibility that LS-DS correlations are due to the common influence of personality traits (e.g. [3]).

\subsection{Subjective well-being and personality}

The five-factor model of personality (Big Five) is the most widely used in SWB studies and certainly provides results about important personality dimensions. However, it is just as certain that there are other personality characteristics not embodied by the big five that are just as worthy of study. To date, a great deal has been learned about the personality traits, values, goals, and social behaviours and cognitions of happy individuals compared to their less happy counterparts (e.g. [4] for review).

It is necessary to stress that overwhelming proportion of the studies on the associations between SWB and personality are conducted in the framework of 'top-down' approach (see [4] for review). The studies of the influence of personality variables on DS are rather rare and leisure/vacation satisfaction is not the exception $[5,6]$.

\subsection{The origin of subjective well-being}

Both bottom-up and top-down theoretical approaches, however, do not explain how personality influences SWB or any of its domains. One possible way of better constructing these theories is by linking them to individual mental maps (models). Mental maps are those core beliefs that may explain how individuals 
select and process information in interpreting life events, and may account for individual differences in these interpretations (e.g. [7]).

Some kind of mental map was used in the model of SWB homeostasis proposed by Cummins et al. [8]. This important theoretical model postulates that SWB fluctuates around a stable set point that is determined by heritable factors such as personality. The homeostasis model couples a primary genetic capacity (neuroticism, extraversion and positive and negative affect) with a secondary buffering system (the cognitive aspects of control, self-esteem, and optimism).

Recent findings in neuroscience and developmental psychology propose some possible explanations of the sources of these thought processes (mental models). Attachment theory explains how children form mental representations of relationships based on their interactions with, and adaptation to, their care-giving environment [9]. Described as internal working models, these cognitive/affective representations are encoded and stored as implicit (unconscious) procedural memories and help organize affect and social experience and shape not only current but future interpersonal relationships [10].

\subsection{Stability of subjective well-being}

Recent research suggests showed that set point theory overstates the stability of happiness and it can, to some degree, be changed [11]. Findings from neuroscience reveal that the brain remains open to new experiences from the environment during the lifespan. This process was called "brain plasticity" or "neuroplasticity" and involves not only the creation of new synaptic connections among neurons but also the growth of new neurons [12]. A wide variety of approaches that have been developed to increase well-being are based on positive psychology concept (see [13] for review).

\subsection{Benefits of traditional tourism for subjective well-being}

It is supposed that holiday trips, vacation as a special type of leisure, pleasant activity potentially add to individuals' happiness [14]. In tourism, a number of scholars $[15,16]$ have examined the benefits of travel based on the bottom-up spillover theory. Neal et al. [15] undertook survey research of tourist satisfaction of travel services and trip experiences and found that tourist's satisfaction of their holiday experiences was related to their life satisfaction scores, which adds some weight to the role of personality traits to understanding links between tourism participation and measures of QOL. Sirgy et al. [16] investigate how positive and negative trip experiences affect overall well-being. Their model illustrates the connections between trip experiences, satisfaction with life domains, and overall satisfaction with life.

More recently several meta-analysis of literature were provided to assess the tourism benefits for quality of life and well-being (e.g. [17]). The main results of these meta-analyses revealed the positive effects of vacationing on perceived quality of life and happiness. However, it has also been found that vacation effects might last for only a few days, two to three weeks, or no more than one month [18]. 
It is important to note here that studies mentioned above were examining the benefits of traditional tourism. If we remember about strong influence of personality (mental models) on subjective well-being and happiness, then the obtained results about the absence of post-trip effect are not surprising. The traditional tourism doesn't aim to influence mental models (personality) of a person. It is simply not that case. We found few studies investigating the influence of personality on leisure satisfaction (e.g. $[19,20])$ and/or vacation satisfaction $[5,21]$, but not vice versa.

\subsection{Wellness tourism}

However, certain types of trips are aimed at relaxation of mind and body, such as wellness trips (e.g. [6]). These types of trips may be more beneficial to an individual's sense of well-being compared to other types of trips. Health tourism, with a focus on good health, general wellbeing and its pursuit, is not a new phenomenon. Health-enhancing practices date back to ancient times (see [22] for detailed overview).

The concept of wellness includes domains such as physical, mental and spiritual health, self-responsibility, social harmony, environmental sensitivity, intellectual development, emotional well-being, and occupational satisfaction [23]. Wellness tourism refers to trips aiming at a state of health featuring the harmony of the body, mind and spirit, self-responsibility, physical fitness, beauty care, healthy nutrition, relaxation, meditation, mental activity, education, environmental sensitivity and social contacts as fundamental elements. These benefits can be enhanced significantly if people engage in health or wellness tourism specifically. That is to say, people travel with the explicit aim or principle motivation of improving their physical and mental condition [24]. Wellness tourism brings with it many new, potentially loaded responsibilities, not just for the normal touristic concerns of transport, accommodation and restaurant standards, but perhaps also for the care of the psyche.

\subsection{Benefits of wellness tourism for subjective well-being}

Although many statements on holistic nature of wellness tourism are declared, the real situation is drastically different. We provided the literature review of the existing wellness services and products and analysed which of them were aimed to manage or improve subjective well-being or wellness. The report of "Wellness Tourism Worldwide" indicates that the most popular wellness tourism services are: beauty treatments; sport and fitness services; leisure and recreational spas, and spa and wellness resorts [25]. Another report on wellness services and products worldwide [22] indicated the following wellness services and products: massage; acupuncture; naturopathy; Ayurveda; meditation; biofeedback; yoga; qigong; deep breathing exercises; guided imagery. Thus it becomes evident that this field, however, is dominated by the traditional biomedical view of health with minimal consideration for positive health and well-being conceptualisations [26]. 
While there are some studies that focus on the relationship between wellness tourism and well-being or health outcomes, most of those studies concentrate on the physical wellness dimension [26]. This is because the medical effectiveness of wellness tourism on physical symptoms has played an important role in destinations where spa cure has a long-standing tradition.

We found only one exception - over 500 wellness retreat centres' data were collated and reviewed in the study [27]. Content analysis of the type of treatments, programs and product offering at retreat centres indicates that a unique product of personal-development/counselling/coaching/confidencebuilding, along with other personal development are offered at a retreat that is different to many others in the wellness tourism sector.

\subsection{Implications of personality for wellness tourism}

Filep [28] specifically recommends the application of positive psychology theories and constructs to the tourism field, which would offer a more balanced view of tourism influences on well-being. Similarly, Pearce [14] has recently argued that tourism researchers and positive psychologists would benefit substantially by interconnecting their knowledge and ideas.

The spa experience is designed to be a healing transformation of the mind, body and soul. Whether in a day, resort or wellness spa, the mental healing service can truly benefit those in need of a mind makeover. And, presented correctly, it can be a new market niche and cash stream for the spa. The object is to promote it as a value-added service and part of the holistic experience. Offering mind analysis and healing techniques as part of spa's menu list broadens the potential for true healing to take place. It is a holistic mind, body, soul approach that fosters the promise for an unforgettable experience.

In addition to positive psychology one more promising holistic approach is body-oriented therapy. The interest in body-oriented approaches for increasing subjective well-being has been growing continuously during the past years. Within the embodiment concept the body is linked directly to thought and subsequently to understanding, and that cognitive processes are intrinsically connected to the body [29].

In the present study we argue that the approach of rhythmic movement therapy (RMT) for increasing subjective well-being [30, 31] can be regarded as highly effective in wellness tourism context. RMT, as well as many other body-centered psychotherapies, view the body as part and parcel of the 'mental' processes that govern the flexibility and range of our response patterns [32]. It means that body literally holds and maintains implicit cognitive, emotional, and perception material that shapes and constrains how we act and that access to and transformation of this material is necessary for increased flexibility and choice in one's life situations.

RMT is a model of psychological intervention that is philosophically and theoretically rooted in body-oriented psychotherapy, dance movement psychotherapy, and rhythmic gymnastics (aerobics) [30, 31]. The therapeutic work in RMT includes two main components: (1) diagnostic system of core personal problems corresponding with various characters and body types and 
(2) rhythmic movement as a medium of change. RMT proposes theory and techniques that allow individuals access deep implicit material and transform related internalized emotional schema (core beliefs). The findings of the previous studies revealed the effectiveness of RMT for the treatment of disordered eating behaviours and obesity [30] and alexithymia [31] and for increasing SWB [33].

The paper unfolds as follows: at first we propose our operationalisation of SWB. It is supposed that the SWB of participants is a multidimensional variable that is composed of evaluations about different domains of satisfaction with life in a bottom-up or component-based approach, where participants appraise in a cognitive and affective way how they experience their lives. Our operationalisation of SWB includes five domains: material, health, work, leisure and recreation and personal competence.

Furthermore, our operationalisation of overall SWB (evaluated in domains) includes dimensions of several psychological constructs that are hypothesised to be components of mental map, underlying SWB, namely level of selfactualisation, sociotropy, perfectionism, locus of control, body dissatisfaction, neuroticism, and alexithymia [4].

The aims of this study are to demonstrate that 1) personality differences can be considered as the mechanisms underlying differences in subjective well-being and 2) rhythmic movement therapy (RMT) can be regarded as effective tool for increasing of SWB level in wellness tourism context.

\section{Method}

\subsection{Participants}

The study was conducted in the framework of Mental Health Management Program organised in the "Human Ecology" department of the Research Center for Interdisciplinary Environmental Cooperation of Russian Academy of Sciences, St. Petersburg, Russia.

At the baseline, a total of 213 subjects were recruited among those searching for counselling (psychotherapy) regarding various non-clinical psychological problems: e.g. low self-esteem, family problems, workplace bullying, etc. No any medical disorders or clinical complaints (e.g. diabetes mellitus, rheumatoid arthritis, pulmonary disease, depression, panic attack, etc.) were claimed by the participants. Demographic items included age and gender, which were assessed with single questions. The participants were aged between 18 and 65 years old, mean age was $36.6 \pm 9.8$ years, $42(20 \%)$ were males and $171(80 \%)$ were females.

The study was approved by the Ethics Committee of I.I. Mechnikov North-West State Medical University, St. Petersburg, Russia, and was performed in accordance with the ethical standards laid down in the 1964 Declaration of Helsinki. All participants signed informed consent form before participating in the study. 


\subsection{Measures}

Subjects were assessed with the measures listed below. Russian-validated translations of all measures were used.

SWB was measured using Integral Index of Social Well-being (IISW) [34]. The test includes 20 items based on a three-point Likert scale and covers five domains of SWB: work, material well-being, health, leisure/recreation and personal competence. Examples of IISW items include 'How satisfied are you with your job?' etc. Two questions reflect the Leisure and Vacation domain: "How satisfied are you with the amount of leisure in your life?" and "How satisfied are you with the length, frequency and quality of vacations you have?" The responses are tabulated as follows: 1 = 'not satisfied'; 2 = 'don't know (not of interest)'; 3 = 'satisfied'. Higher scores show higher level of SWB, maximum score is 60.0 . The IISW has demonstrated strong internal consistency and testretest reliability $(0.67)$. In the experimental sample, the IISW items generated alpha coefficients of 0.87 [34].

The Personal Orientation Inventory (POI) [35]. In the present study, only the main scales were used because Shostrom [35] recommended that the Time Competence $(T c)$ and Inner-Directed $(I)$ scales may be used when a quick estimate of examinees' levels of self-actualization is desired.

General Locus of Control Scale of the Locus of Control Inventory (LOC) was used to measure locus of control because it uses all the items in the LOC and is the only LOC scale that does not have overlapping items [36].

The Neuroticism (N) Scale was selected from the Eysenck Personality Inventory (EPI [37]) to measure the traits of extraversion-introversion and neuroticism. Scores range from -12 to 12 .

Alexithymia was investigated using the Toronto Alexithymia Scale-26 (TAS-26) [38]. The TAS-26 is a 26-item self-report measure of alexithymia with a three-factor structure theoretically congruent with the alexithymia construct. A cut-off score of 62 was used to define alexithymia as recommended.

Body Image Test [39] was used to investigate body image dissatisfaction. Participants answered how often they felt uncomfortable about their appearance in different situations. The test includes 20 items, which are answered based on a four-point Likert scale. Higher scores show greater body image dissatisfaction.

Personal Perfectionism Scale (PPS) includes three subscales from the Multidimensional Perfectionism Scale by Frost et al. [40]: 'Personal Standards', 'Concern over Mistakes' and 'Doubts about Action' and 'Concern over Mistakes' and 'Doubts about Actions' subscales were combined into one scale. Thus, PPS includes 20 items, which are answered based on a seven-point Likert scale. The reliability and validity of the Russian version of the PPS were described in our previous study [30].

Sociotropy Scale of Personal Style Inventory (PSI [41]) was used to assess the constructs of sociotropy. The PSI Sociotropy Scale consists of 24 items which are rated on a six-point Likert scale. Higher scores show greater chance of sociotropy. 
Participants were given approximately 1 hour to complete the scales described above.

\subsection{Statistical analysis}

Statistical analyses of the obtained data were carried out using SPSS 16.0 for Windows. Prior to completing analyses, all the obtained data were checked for normality (Kolmogorov-Smirnov test), homogeneity of variances (Levene's test), sphericity (Mauchly's test of sphericity) and equality of the covariance matrixes across groups (Box's M-test). Bivariate, two-tailed correlations were used to investigate the strength of the associations between leisure/vacation satisfaction and overall subjective well-being. A one-way ANOVA was used for between-group comparisons.

After assessment all subjects of experimental group were divided into two groups in accordance with their SWB level: group 1- (20-40 IISW scores mean very low, low and medium SWB levels) - 96 subjects, 75 females, 21 males, mean age $36,3 \pm 11,0$ years) and group 2 - (41-60 scores of IISW mean high and very high SWB levels) - 117 subjects, 96 females, 21 males, mean age 36, $8 \pm 8,68$ years. Two types of ANOVA analyses were provided: with SWB group as a factor and with gender as a factor.

\section{Results}

Leisure/vacation satisfaction was significantly positively associated with overall subjective well-being $(r=0.597, p<0.01)$.

Table 1: Table assessment scores in groups 1 and 2.

\begin{tabular}{|l|c|c|c|c|}
\hline $\begin{array}{l}\text { Psychological variables, IISW and } \\
\text { Leisure/Vacation Satisfaction }\end{array}$ & $\begin{array}{c}\text { Group 1 } \\
\text { N=96 } \\
\text { M (SD) }\end{array}$ & $\begin{array}{c}\text { Group 2 } \\
\text { N= 117 } \\
\text { M (SD) }\end{array}$ & $\begin{array}{c}\text { ANOVA } \\
\boldsymbol{F ( 1 , 2 1 2 )}\end{array}$ & $\boldsymbol{p}$ \\
\hline Integral index of social well-being & $38.8(3.7)$ & $50.3(3.9)$ & 473.2 & $<0.001$ \\
\hline Time competence & $7.1(3.2)$ & $8.8(2.8)$ & 18.7 & $<0.001$ \\
\hline Inner-directedness & $41.5(10.2)$ & $49.6(9.5)$ & 35.9 & $<0.001$ \\
\hline Sociotropy & $92.3(16.0)$ & $80.5(17.3)$ & 26.3 & $<0.001$ \\
\hline Personal standards & $21.7(5.5)$ & $20.9(4.6)$ & 1.5 & 0.224 \\
\hline $\begin{array}{l}\text { Concern over mistakes/ } \\
\text { doubts about actions }\end{array}$ & $37.5(10.2)$ & $28.3(8.6)$ & 51.1 & $<0.001$ \\
\hline General locus of control & $4.6(1.7)$ & $6.2(1.6)$ & 50.6 & $<0.001$ \\
\hline Body image dissatisfaction & $20.3(12.2)$ & $15.2(11.7)$ & 9.6 & 0.002 \\
\hline Neuroticism & $3.5(4.7)$ & $0.33(4.6)$ & 25.9 & $<0.001$ \\
\hline Alexithymia & $66.3(12.1)$ & $58.5(11.2)$ & 23.9 & $<0.001$ \\
\hline Leisure/vacation satisfaction & $3.0(1.1)$ & $4.6(1.5)$ & 73.6 & $<0.001$ \\
\hline
\end{tabular}

After the groups 1 and 2 were formed, the results of one-way ANOVA with group as a factor in entire sample indicated no differences in SWB level due to age $(F(1,212)=0.14, p=0.71)$ or $\operatorname{gender}(F(1,212)=0.51, p=0.48)$. The 
ANOVAs demonstrated that subjects of group 1 compared with the subjects of group 2 have significantly different levels of SWB as well as of all other personality variables, except for "Personal standards" (Table 1). 0

The results of ANOVA with gender as a factor didn't indicate any significant differences between males and females in all variables under study $(p>0.05)$ except for body image dissatisfaction. The scores of this variable in female group are equal $19.4 \pm 12.3$, in male group $-9.9 \pm 7.9, F(1,212)=22.4, p<0.001$.

\section{Discussions}

Our result of the significant association of SWB with several personality variables is consistent with many other results. Results of several studies revealed the significant associations between SWB and neuroticism, high self-directedness and time competence, external locus of control, low levels of alexithymia, body image dissatisfaction, sociotropy and perfectionism (see [4] for review). Thus, we suppose that our specific operationalisation of SWB construct has merit. Our research provides evidence that thinking styles (mental models) may significantly influence SWB. Their role is not directly included by existing psychological theories of subjective well-being. This particular result provides at least partial explanation how personality may be linked to SWB.

Another purpose of this study was to explain the potential efficacy of RMT intervention for increasing SWB as a part of wellness service. Body-oriented psychotherapies for increasing SWB are rather rare. Nevertheless, our findings of RMT effectiveness are generally consistent with the results of several other studies in the field. RMT relies on body-based mindfulness as a primary tool to explore the implicit beliefs that organize life experiences and to address the attachment injuries that shape our emotional realities. Mirror neuron research has pointed toward a strong neuronal connection between one's own motor experience and intersubjective and empathic processes [42]. Our results on differences in body-image dissatisfaction between males and females give additional basis for importance of body-oriented approaches in holistic wellness healing. The findings of the previous studies revealed the effectiveness of RMT for the treatment of disordered eating behaviours and obesity [30] and alexithymia [31] and for increasing SWB [33].

The study limitations highlight the need for future research in this area of SWB. One limitation of our research is that we only provide a partial explanation for the influence of thought processes (personality) on SWB. The second limitation is that we provide only theoretical background for RMT as effective service in wellness tourism context. The further experimental studies are needed.

\section{Conclusions}

In general, individual differences play an important role in determining the manner in which people react on life circumstances and then play out in turn in the SWB that is experienced. Our research provides evidence that thinking styles (mental models) may significantly influence SWB and any program for its 
increasing must include mental healing service. Theoretical background provided for RMT as effective part of wellness service can be regarded as a good starting point for further studies in this field.

\section{References}

[1] Diener, E. Subjective well-being. Psychological Bulletin, 95, pp. 542-575, 1984.

[2] Diener, E., Suh, E.M., Lucas, R.E. \& Smith, H.L. Subjective well-being: Three decades of progress. Psychological Bulletin, 125, pp. 276-302, 1999.

[3] Schimmack, U., Diener, E. Oishi, S. Life-satisfaction is a momentary judgment and a stable personality characteristic: The use of chronically accessible and stable sources. Journal of Personality, 70(3), pp. 345-384, 2002.

[4] Malkina-Pykh, I.G. \& Pykh, Yu. A. The Method of Response Function in Psychology and Sociology. Southampton, Boston: WIT Press, 2013.

[5] Dolnicar, S., Yanamandram, V. \& Cliff, K. The contribution of vacations to quality of life. Annals of Tourism Research, 39 (1), pp. 59-83, 2012.

[6] Nawijn, J. Leisure Travel and Happiness. An Empirical Study into the Effect of Holiday Trips on Individuals' Subjective Wellbeing. Dissertation Erasmus University Rotterdam, 2012.

[7] Erez, A., Johnson, D.E. \& Judge, T.A. Self-deception as a mediator of the relationship between dispositions and subjective well-being. Personality and Individual Differences, 19(5), pp. 597-612, 1995.

[8] Cummins, R.A., Gullone, E. \& Lau, A. L. D. A model of subjective well-being homeostasis: The role of personality. In: E. Gullone \& R.A. Cummins (Eds.), The Universality of Subjective Wellbeing Indicators: Social Indicators Research Series. Dordrecht: Kluwer, pp. 7-46, 2002.

[9] Bowlby, J. Attachment and Loss. I: Attachment. New York: Basic Books, 1969.

[10] Schore, A.N. The neurobiology of attachment and early personality organization. Journal of Prenatal and Perinatal Psychology and Health, 16(3), pp. 249-263, 2002.

[11] Diener, E., Lucas, R.E. \& Scollon, C. Beyond the hedonic treadmill: Revising the adaptation theory of well-being. American Psychologist, 61, pp. 305-314, 2006.

[12] Barbas, H. Anatomic basis of cognitive-emotional interactions in the primate prefrontal cortex. Neuroscience and Biobehavioral Reviews, 19, pp. 499-510, 1995.

[13] Sin, N.L. \& Lyubomirsky, S. Enhancing well-being and alleviating depressive symptoms with positive psychology interventions: A practicefriendly meta-analysis. Journal of Clinical Psychology, 65, pp. 467-487, 2009.

[14] Pearce, P.L. The relationship between positive psychology and tourist behavior studies. Tourism Analysis, 14(1), pp. 37-48, 2008. 
[15] Neal, J., Sirgy, M. \& Uysal, M. The role of satisfaction with leisure travel/tourism services and expenditure in satisfaction with leisure life and overall life. Journal of Business Research, 44, pp. 153-163, 1999.

[16] Sirgy, M.J., Kruger, P.S., Lee, D.-J. \& Grace B. Yu. How does a travel trip affect tourists' life satisfaction? Journal of Travel Research, 50(3), pp. 261-75, 2011.

[17] Chen, C.-C. \& Petrick, J.F. Health and wellness benefits of travel experiences: A literature review. Journal of Travel Research, 52(6), pp. 709-719, 2013.

[18] Nawijn, J. Determinants of daily happiness on vacation. Journal of Travel Research, 50(5), pp. 559-566, 2011.

[19] Kovacs, A. The Leisure Personality: Relationships between Personality, Leisure Satisfaction, and Life Satisfaction. $\mathrm{PhD}$ Thesis, Indiana University. School of Health, Physical Education, and Recreation, 2007.

[20] Moghadam, M.B. Exploring relationship of personality's models and constructs of leisure. Middle-East Journal of Scientific Research, 8(2), pp. 530-535, 2011.

[21] Reisinger, Y. \& Mavondo, F. Modeling psychographic profiles: A study of the U.S. and Australian student travel market. Journal of Hospitality \& Tourism Research, 28(1), pp. 44-65, 2004.

[22] Global Spa Summit, Spas and the Global Wellness Market: Synergies and Opportunities, prepared by SRI International, May 2010.

[23] Mueller, H. \& Kaufmann, E. (2001). Wellness tourism: Market Analysis of a special health tourism segment and implications for the hotel industry. Journal of Vacation Marketing, 7(1), pp. 5-17, 2001.

[24] Smith, M., \& Puckzo, L. (Eds.). Health and Wellness Tourism. Oxford: Butterworth-Heinemann, 2008.

[25] The 4WR: Wellness for Whom, Where and What? Wellness Travel 2020 Full Report is prepared for Wellness Tourism Worldwide by Xellum Ltd. (Hungary) with the support from Global Spa and Wellness (USA), 2011.

[26] Voigt, C. Understanding Wellness Tourism: An Analysis of Benefits Sought, Health-Promoting Behaviours and Positive Psychological Well - Being. PhD Thesis. University of South Australia, 2010.

[27] Kelly, C. Analysing wellness tourism provision. A retreat operators' study. Journal of Hospitality and Tourism Management, 17, pp. 108-116, 2010.

[28] Filep, S. "Flow", sightseeing, satisfaction and personal development: Exploring relationships via positive psychology. Paper presented at the CAUTHE 2007: Tourism: Past Achievements, Future Challenges, 2007.

[29] Koch, S. \& Fuchs, T. Embodied arts therapies. The Arts in Psychotherapy, 38(4), 276-280, 2011.

[30] Malkina-Pykh, I.G. Effectiveness of rhythmic movement therapy for disordered eating behaviours and obesity. The Spanish Journal of Psychology, 15, pp. 1371-1387, 2012.

[31] Malkina-Pykh, I.G. Effectiveness of rhythmic movement therapy: Case study of alexithymia. Body Movement and Dance in Psychotherapy, 8, pp. 141-159, 2013. 
[32] Mowrer, J. Accessing implicit material through body sensations: The body tension sequence. Hakomi Forum, 19-20-21, 2008.

[33] Malkina-Pykh, I.G. Effectiveness of rhythmic movement therapy: Case study subjective well-being. Body Movement and Dance in Psychotherapy, 2014, under review.

[34] Panina, N. \& Golovakha, E. Tendencies in the Development of Ukrainian Society (1994-1998), Sociological Indicators. Kyiv: Institute of Sociology, 2001.

[35] Shostrom, E. Personal Orientation Inventory: Manual. San Diego: Edits, 1974.

[36] Rean, A.A. Handbook of personality assessment. Saint-Petersburg: SaintPetersburg University Press, 2001.

[37] Eysenck, H.J. \& Eysenck, S.B.G. Manual of the Eysenck Personality Inventory. London: University of London Press, 1963.

[38] Taylor, G.J., Ryan, D.P. \& Bagby, R.M. Toward the development of a new self-report alexithymia scale. Psychotherapy and Psychosomatics, 44, pp. 191-199, 1985.

[39] Jade, D. (2002). How good is your body image? http://www2.netdoctor.co. uk/testyourself/facts/body_image.asp. Accessed 20 February 2012.

[40] Frost, R.O., Marten, P., Lahart, C. \& Rosenblate, R. The dimensions of perfectionism. Cognitive Therapy and Research, 14, pp. 449-468, 1990.

[41] Robins, C.J., Ladd, J., Welkowitz, J., Blaney, P.H., Diaz, R. \& Kutcher, G. The Personal Style Inventory: Preliminary validation studies of new measures of sociotropy and autonomy. Journal of Psychopathology and Behavior Assessment, 16, pp. 277-300, 1994.

[42] Gallese V. The roots of empathy: the shared manifold hypothesis and the neural basis of intersubjectivity. Psychopathology, 36, pp. 171-180, 2003. 